\title{
ENHANCING THE PRONUNCIATION OF ENGLISH SUPRASEGMENTAL FEATURES THROUGH REFLECTIVE LEARNING METHOD
}

\author{
Suwartono*, Zainal Rafli** \\ Universitas Muhammadiyah Purwokerto, Indonesia* \\ Universitas Negeri Jakarta, Indonesia** \\ suwartono2006@yahoo.co.id* \\ zainal.rafli@gmail.com**
}

\begin{abstract}
Suprasegmentals are of paramount importance in spoken English. Yet, these pronunciation features are marginalised in EFL/ESL teaching-learning. This article deals with a study through reflective learning method and That aims to describe the increase in supramental english skill find out if the improvements achieved in the english pronounciation. Kemmis and Taggart's model of action research was adopted. The study involved twenty-four undergraduate students at Muhammadiyah University of Purwokerto, Indonesia. The investigation contained two cycles, each of which comprised three sessions. Data were gathered through observation, recorded conversation, diary, interview, and test. Overall, the study has shown that reflective method using video integrated into communicative activities enhanced student involvement in learning the pronunciation of English suprasegmentals. Students got involved in monitoring and evaluating their own learning. In addition, a majority of the students gave positive response to the instruction. Level of pronunciation mastery rose sharply from only $4.16 \%$ of students passing the test in the pre-intervention (baseline) to $65.21 \%$ in first cycle, and $73.9 \%$ in second cycle. Most students' pronunciation to some degree sounded "more English".
\end{abstract}

Keywords: suprasegmentals, reflective, involvement, monitoring, evaluating.

Pronunciation might be the most marginalised in the teaching and learning of English, in spite of a key role this language aspect plays in spoken communication. The neglect for teaching pronunciation may be due to the apparent complexity of English pronunciation and a misconception about what the content of a pronunciation course should be and about the way pronunciation should be taught. Within this "Cinderella” aspect of language, perhaps segmentals are luckier, in that they are more taught and better researched than suprasegmentals. However, suprasegmentals are worthier of attention mainly because these features contribute heavily to intelligibility in spoken English and convey better impression of the speaker (O’Neal, 2010: 65-87). It means improving the pronunciation of English suprasegmentals can facilitate communication, boost self esteem, and possibly lead to a better future. Therefore, within the context of spoken English communication, suprasegmental features should be given priority or, at least, equality.

Apart from the significance of wisely treating English suprasegmental features, several problems emerged in the author's teaching of suprasegmental features: uninteresting lessons, lack of listening to model activity prior to production practice, greater portion of teacher talk time, and too much drill. A formative test on connected speech showed a very low result, with only one student (4.16\%) achieving existing standard. An effort to solve the problems was made through the adoption of 
reflective learning method using video as a reflective tool incorporated into oral communicative language activities.

The term 'reflective' (as it appears in 'reflective learning'), used interchangeably with 'reflection' in the educational context, is associated with deep learning. In deep learning, the intention of the learner is to develop a personal understanding of the material and relate it to what is already known. In other words, experience is central in reflective learning. It has something to do with Kolb's concept of experiential learning, in which the learner's immediate experience is taken as the focus of learning, giving life, texture, and subjective personal meaning to abstract concepts and at the same time providing a concrete reference point for testing the implications and validity of ideas created during the learning process (Benson, 2001: 38).

Dewey as cited by Hillier (2002: 17-18) identified five general features of reflection or reflective thinking: (1) perflexity/doubt due to the fact one is implicated in an incomplete situation whose character is not fully determined; (2) conjectural anticipation, i.e. a tentative interpretation of the elements; (3) examination/exploration or analysis of all attainable considerations which will define and clarify the problem at hand ; (4) consequent elaboration of the tentative hypothesis; and (5) taking one stand upon the projected hypothesis as a plan of action, doing something overtly to bring about the anticipated result and thereby testing the hypothesis. This implies that the act of reflecting is not just a simple rushing into a trial-and-error approach. It is a way of minimising surface approaches.

In connection with the teaching of the pronunciation of English suprasegmental phonemes, being engaged in reflection process students will make use of existing experience for testing ideas and assumptions exploratively. They, though in uncertain situations or in trouble with such features (e.g. intonation, rhythm, and stress) which are indisputably commonly considered complicated to master, will strive for a solution, a commitment to continuous learning by seeking new ideas, evaluating and reflecting on their impact and trying out new practices and ways of learning to improve their own effectiveness in the learning environment.

Cercone (2008: 137-159) notes that adults need to self-reflect on the learning process. For this, she suggests that instructors provide ways most possible for learners to engage in metacognitive reflection such as the use of logs and reflective journals. In the present study, video is chosen to help create a condition which best favors reflective learning. Video has fixative property, with which it can record, save, and reproduce information when needed (Suwatno, 2012: 63-68). With these characteristics students can utilize video to record, play and replay events.

In recounting situations, the immediacy of the moment recorded in video is not lost, as is the behavior in relation to the emotion/feeling. This provides the opportunity to talk through the experience. In this way, the adult learners/students can be motivated to learn by internal rewards, such as increased self-esteem and a sense of accomplishment. By using the recorded communicative events, students have video feedback on their development. This also highlights their strengths, which often they find so easy to ignore. They can then modify their behavior accordingly, either in isolation or with support of teacher and/or peers. Facial expressions and gestures that often accompany accented utterances will be of special interest to students. This all helps raise learners' awareness. True, awareness develops in adult but not in child (Thompson and Gaddes, 2005: 1-5). However, 
degree of reflectivity can be boosted with reflection process. It is for this reason teachers should promote and take control over students' reflection process so that their self-awareness becomes optimized. With adequate awareness learners are able to self-monitor and self-evaluate their own learning. Monitoring and evaluating is an essential element of reflection process.

Reflection is even stronger when the learning of suprasegmental pronunciation is incorporated into oral communication activities that include both reception and production practices. By playing a target model recording, for instance, students can listen and watch and get insight into target linguistic and nonlinguistic (nonverbal) input that is useful for their production. Alip (2009: 133138) argues for the value of receptive activity prior to productive task in the teaching of English suprasegmentals pronunciation. A seemingly similar study by Wulandari et al (2008: 1-10) has shown that teaching English pronunciation using audio visual aids resulted in improved suprasegmentals, notably intonation and stress. The currrent study was aimed at describing the raising of English suprasegmental features through reflective learning method and finding out whether improved pronunciation of these features can be achieved through this method.

\section{METHOD}

The main goal of this research was to improve the teacher's instructional practices. Action research was chosen because it is a type of practioner research that is is used to learn and improve classroom practioner's own teaching activities (Gay and Airasian, 2000: 593). The Kemmis and Taggart's model of action research was adopted. The study involved twenty-four second semester students of Class C2 at the English Language Education Department of Muhammadiyah University of Purwokerto, Indonesia attending Pronunciation 2 course in the 2011/2012 academic year. As part of an initial reflection of the teaching practice, a preliminary observation was conducted by a colleague (the outside-researcher) in the author's pronunciation class to record the pre-intervention condition and help identify problems. The collaborative study contained two cycles, each of which comprised three weekly a hundred-minute sessions.

The outside-researcher participated in most activities of the research. Main learning activities/tasks in each session covered listening to target model, rehearsing monologue or a dialogue, video-recording, and playing video clip. Scripts were provided just to help the students memorise what to say. Videos available on the campus language labs' computers were made use to facilitate reflection process in the part of students.

Two types of data were gathered: data on teaching and learning process (qualitative data) and data on learning outcome (quantitative data). The research qualitative data included teaching and learning activities, teacher's behavior, and student's behavior and perception, while the quantitative data dealt with the test result. Qualitative data were elicited through observation, reflective diary, and interview, while the quantitative data were collected through recorded conversation task and test.

Observations were done by the outside-researcher using checklist. The students were provided with small notebooks for writing diary and given necessary 
direction. Interviews with some students were carried out by the outside-researcher in order that the interviewees feel free in giving response. Monologue or dialogue practice video clips handed in by the students were reviewed, scored and then given written or oral feedback. Tests were administered before and after each cycle and scored by the outside-researcher and the teacher-researcher independently. The technique employed in the test was reading aloud. A right answer was scored 1, whereas a wrong answer 0 . To reduce inconsistency, both raters equipped themselves with guidelines developed beforehand.

Qualitative data were analysed via analytic induction methods to identify common themes and to extract narratives of experience. Quantitative data were analysed to calculate statistical frequencies, percentages, and means. Triangulation - more than one methods of investigation - was employed to establish validity of the research (Bryman, 1988: 131-134), namely investigator triangulation and method triangulation.

\section{RESULTS}

In regard to the use of reflective learning method in this action research study, the intervention was a successful attempt to improve the pronunciation of English suprasegmental features. Reflective learning method using video integrated into communicative, meaningful language activities has encouraged student involvement in the learning process. Involvement was primary concern of the pre-intervention condition. Student involvement increased as most observed behavior was detected during teaching-learning process. Behavior that fostered student involvement included answering questions, spontaneously responding learning tasks, seriously doing in-class works, and completing learning tasks on time. Figure 1 shows the average occurences of each type of behavior per cycle.

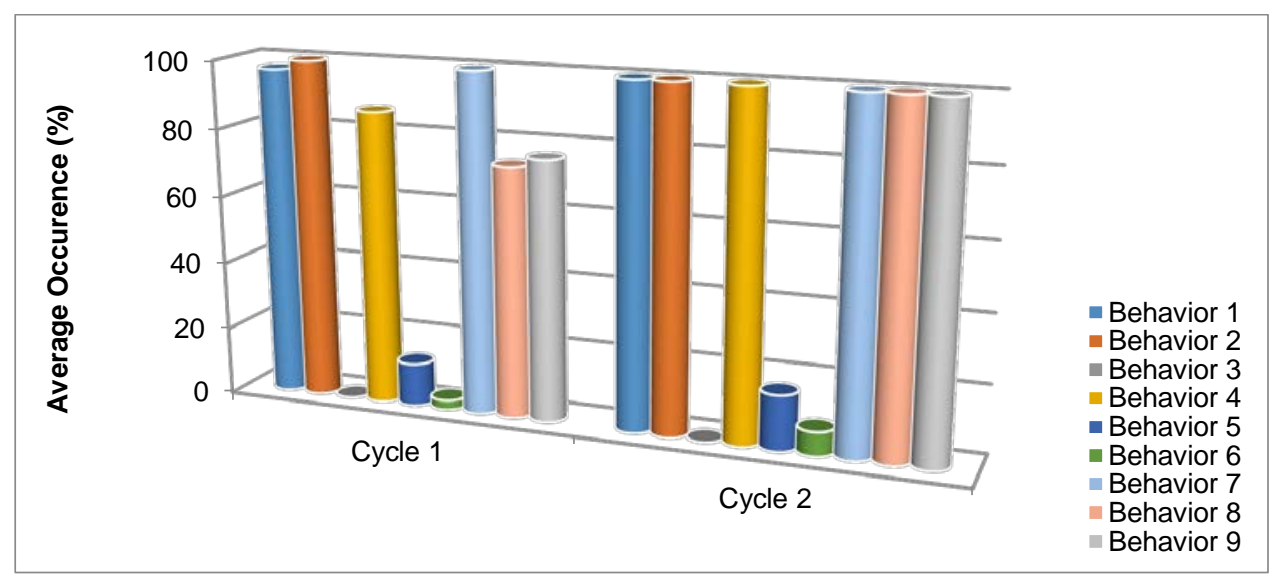

Figure 1. Number of Occurences of Behavior by Type per Cycle

Until the end of intervention implementation, three types of observed behavior: student question raising, feedback giving and self-criticism or selfcorrection remained a problem even though certain effort had been taken. Within six 
sessions no students seemed to show initiative for raising questions (behavior 3) and a few gave feedback to peers (behavior 5) and commented on own performance or self-corrected own errors (behavior 6).

Dealing with student learning process, in first cycle the indicator against agreed criteria for success of intervention: students' activity in following the teaching-learning process reaches an average of at least $60 \%$ was not fulfilled (57.37\%<60\%). Minor revisions in intervention implementation eventually brought about better teaching-learning quality in second cycle. As can be seen from Figure 2 below, number of behavior identified from session to session tended to increase.

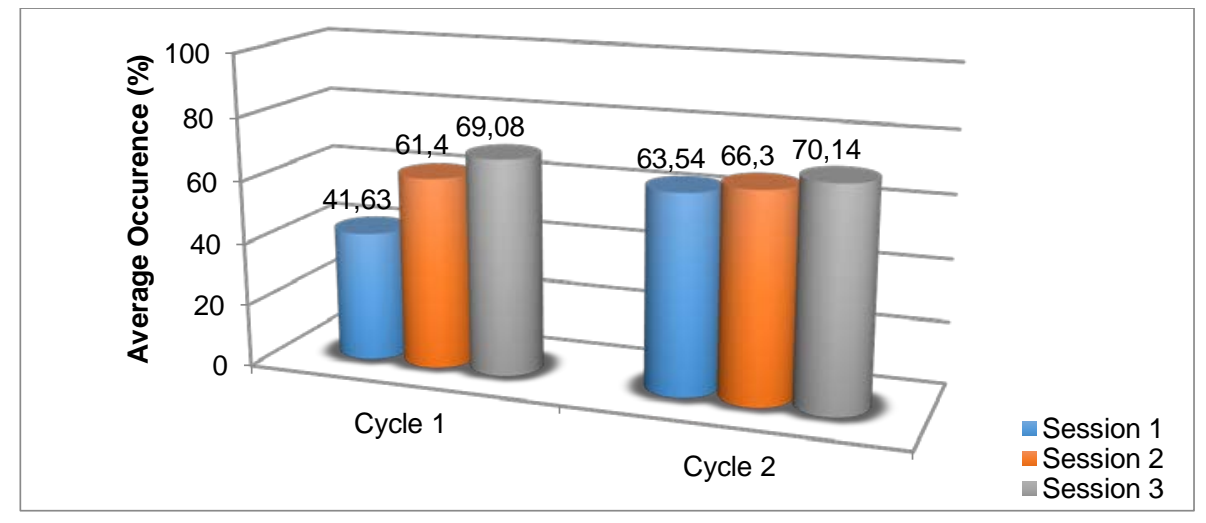

Figure 2. Number of Occurences of Behavior per Session

It is interesting to see that a majority of the students gave positive response to the instruction adopted. Based on the data elicited through diary, five to six categories of response have been identified, as illustrated in the figure below.

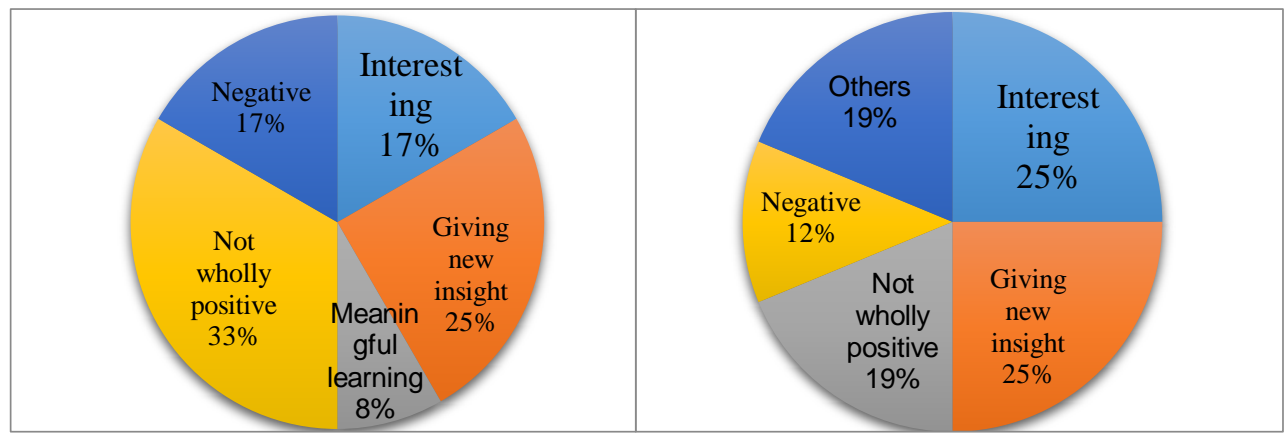

Figure 3. Sample of Student Responses to the Instruction

"Not wholly positive" constituted responses that contained partly negative responses. "Others" were responses that seemed irrelevant or did not fall into any category already mentioned, for example notes on stress patterns, or personal health. Figure 3 above shows that positive responses make up around 50 to 83 percent of the whole responses at the end of first cycle (left) and 50 to 69 percent at the end of second cycle (right).

The improved learning process was followed by a rise in learning outcome. From the pre-intervention formative test result (baseline), it was revealed that only 
4.16\% of the students passed, i.e., those achieving a score no less than 50 (left). It rose sharply up to $65.21 \%$ in first cycle, and increased to $73.9 \%$ in second cycle. The average score reached was 16.25. It increased up to 53.7 in first cycle, and slightly went up to 57.17. It means the students' pronunciation mastery improved from cycle to cycle. Since the other indicator against preset criteria for success of implementation intervention was: $60 \%$ of students get minimum score of 50, this standard had already been met in first cycle. Figure 4 shows the students' pronunciation mastery before and after intervention.

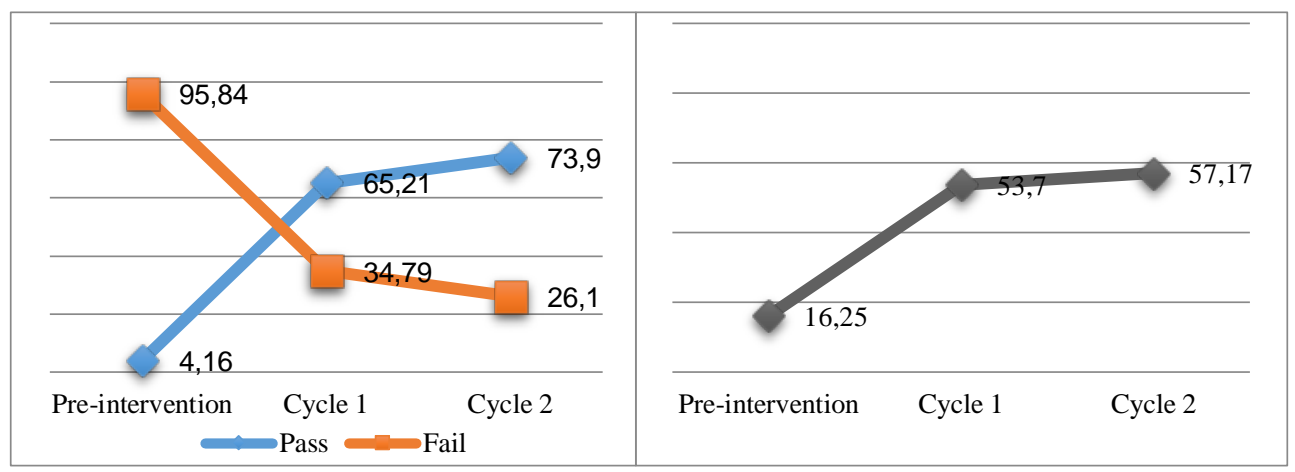

Figure 4. Students’ Pronunciation Mastery of English Suprasegmentals

It is wise to value the gain from first to second cycle, as the material taught in second cycle, i.e. stress, is considered more complicated compared to the one taught in the previous cycle, i.e. intonation. A student commented in native language in the diary: “... Today I am learning the stress of English. I think it is more complicated than intonation...”

Within two cycles the students' result of doing in-class learning tasks reached an average score of 3.86 (using a 5 point scale), whereas the outside class work conversation recordings submitted in the last session of each cycle showed some students' pronunciation has been much better than ever before the intervention was adopted. Their speech became no longer flat, filled with intonation and stress. Better segmental and suprasegmental features (i.e. connected speech) that had been previously poor were also heard in their speech. In short, students' pronunciation to a some extent sounded "more English”.

\section{DISCUSSION}

The improved student involvement in the learning process after reflective learning method was adopted was thought to be attributable to the opportunity for using language through listening to/watching target models activity prior to production. In addition to insight into the target language in use, the students took advantage of the spoken texts as aural linguistic input along with nonlinguistic input, such as facial movement and gestures for use in production later. This could raise self-confidence in giving oral response. Having listened to native speaker target models recording, the students almost spontaneously and enthusiastically answered questions asked by the teacher about the recording. That is why, when listening to a 
segment of video file containing news reading whose speech was too fast for his/her level, a student wrote the following complaint in native language in the diary: '...but when the video was being played I could not follow a lot just because it was too fast, so I could not catch the words.' This means the necessity for a better teaching preparation in order that learning is optimum. However, the listening/watching activity prior to productive activity was a quite useful receptive skill practice to the students. This is in line with what Alip (2009: 133-138) argues for in another section of this article.

The students also benefited from the teaching and learning method that provided pronouncing experience in oral activities, though just rehearsing a monologue or dialogue in front of video camera. Pronunciation teaching was not explicit any more. Instead, it was immersed in spoken communication activities. This is highly consistent with the views of many researchers and experts, including Derwing (2009: 24-37) that teaching pronunciation should be integrated into oral communication skills. When making a video clip task came, the students looked eager to respond it and busy as well as serious to rehearse the text, record, review and correct their own production. Noise and serious faces were all the atmosphere of the class during this period of recording making. This was the impact of active envolvement in doing learning tasks, which was rooted in reflective learning process created. The students became accustomed to recognising suprasegmental features produced by speakers in the target model video files, then trying out the ways the speakers pronounce the suprasegmentals, critically reviewing production (i.e. comparing own production to target model) and self-correcting or mutually correcting with peers in teaching and learning activities.

Interestingly enough, this part of the lessons was always longed for by the students. A student wrote this: 'Making a video clip, it is fascinating. I can express...' While making a recording, the students listened to/watched themselves on the computer monitor verbal as well as nonverbal expressions produced. Having finished recording, they immediately replayed their recording (perhaps more than once), critically reviewed their speech and nonverbal expressions, quite possibly remembered prior errors, and corrected or refined them. In other words, the students carried out self-monitoring and self-evaluation for the pronunciation of English suprasegmental phonemes: on-line listening or monitoring (while speaking), off-line monitoring (after speaking), evaluating (whether criteria are being fulfilled), and correcting orally. With pronunciation model as found on the recording that was played before converstation recording activity (and already available on each lab's computer in the last session), it was assumed that progress checking process or monitoring and evaluating learning the pronunciation of suprasegmental phonemes, i.e. English intonation and stress patterns, by the students went on well.

As adult learners, the students took advantage of the development of selfawareness in the form of self-monitoring and self-evaluation, that does not exist in children (Thompson and Gaddes, 2005: 1-5). Their self-awareness was fostered by reflective learning method adopted. Self-monitoring and self-evaluating was associated with ability to manage learning (Wenden, 1991: 25-28). In the teaching of suprasegmental pronunciation adopting reflective learning method, most of the students perceived that they were self-aware of what was going on during, after and before learning. A student commented: 'My speech is a mess, but I am trying again. Honestly, I want this way of learning to take place so often that I get accustomed to 
speaking English, instead of nontarget-like English.' Some students not only expressed learning difficulty being encountered, but also a clear plan, as in the following '...today's lesson is confusing because verb and adjective stress seems uncertain. Need to learn much from dictionary, the internet, or wherever...' The students' capacity for managing their own learning has developed fast; hence, it is not hard to assume that the students' learning and practice has extended to outside classroom context.

One concern that emerged in the intervention implementation was the absence and lack of occurence of those three types of observed behavior, in spite of a particular effort done. However, relative to cultural perspectives, perhaps it is understandable. Indonesia has emerged as one of the most collectivist societies (Giles, 2003: 1-6). According to Lee (2011: 75-81), in most collectivist cultures the people worry about losing face. Student culture exerts a potent effect on behavior in class. Taking this perspective into account, quite possible students in the current study were afraid of losing face, so they avoided asking questions. If they asked questions it could mean showing-offs. If a student asked questions in class, it may also have been regarded as losing face because it indicated that only he/she was not able to follow the lesson.

A student commented: 'I am still a bit confused, but if I want to ask a question to Mr. Ton using English I am afraid of making mistakes.' This was written in the diary in the last session of second cycle. It was a proof that the effect of the culture was so strong that the students got upset and forgot they later had been permitted to ask in native tongue, and on a piece of paper if intended.

In a previous study at secondary level, the similar crisis of self-confidence to ask questions had been resolved through encouragement and material reward, i.e. snack (Suwartono and Mayaratri, 2011: 24-31). Nonetheless, this was not fully applied to the present research considering that it would not work equally well to adult learners. Giving extra points was chosen instead. Asking questions in class needs strong courage. A less self-confident student would rather wait than ask a question even when he/she does not understand something. This hinders learning, as things remained puzzled. Some data elicited through diaries also led to a conclusion that some students still encountered learning difficulties.

Still according to Lee, in collectivist cultures quite rarely students in class would take the initiatives; usually they just keep silent. They are often reluctant to answer questions, do not express their opinions freely in class. Bearing the finding above in mind, those three types of culturally bound behavior are a challenge which faces teacher-researchers, in this case those who work in the context of Indonesia.

The problems that emerged in the pre-intervention condition were no longer found in the teaching-learning of pronunciation of English suprasegmental phonemes through reflective learning method. Previously, the "menu" of classroom activity was not appealing; after reflective method was applied, the students perceived that the classroom instruction was fascinating. The students had received inadequate listening to model activity prior to production practice; in the reflective learning, on the other hand, listening to/watching short segment of video file was a routine. Additionally, the greater portion of teacher talk time, too much drill, and teacher-centered activity in the former teaching-learning process was replaced by communicative, meaningful teaching-learning process through conversation video recording task in reflective learning practice. 
The better learning quality by using reflective method has impact on students' mastery of suprasegmental features being taught. Sufficient result of doing in-class learning tasks has affected their performance in completing outside-class task. An outside class pair-work conversation recording made by two very weak students in first cycle, for example, contained mostly accented and connected utterances. Even, in second cycle outside class work conversation video clips, another student managed to use intonation, stress, and connected speech nearly perfectly. With this improved use of intonation, stress, and connected speech, most students' pronunciation of English was to some extent no longer a strong Indonesian or Javanese accent. Their utterances were less spoken in monotones and melodies of varying kinds became more often heard, with the voice rising and falling. In other words, their pronunciation sounded foreign-accented to some degree, "more English”. In a previous study on connected speech by the author, it was revealed that songs helped students learn English connected speech (Suwartono, 2012: 149-151). It shows how creativity in the part of teacher is vital.

\section{CONCLUSION}

To sum up, overall, the reflective learning method using video incorporated into oral communication activities has improved student learning process of English suprasegmental phonemes. The method adopted has boosted students' involvement in learning the pronunciation of English suprasegmental phonemes. The students got involved in adequate language practice and monitoring as well as evaluating their own learning. In addition, a majority of the students gave positive response to the instruction adopted.

The students' pronunciation mastery of English suprasegmental phonemes considerably increased and reached the preset standard. With sufficient improvement in the mastery of suprasegmentals, notably intonation and stress, the converstation video clips handed in have apparently shown that most students' English pronunciation to some extent sounded “more English”.

\section{REFERENCES}

Alip, Francis Borgias. 2009. “Introducing Segmental and Suprasegmental Aspects of English Phonology to Indonesian Students.” Proceedings of the UAD TEFL National Conference.

Benson, Phil. 2001. Teaching and Researching Autonomy in Language Learning. Harlow: Pearson Education Limited.

Bryman, Alan. 1988. Quantity and Quality in Social Research. London: Unwin Hyman Ltd.

Cercone, Kathleen. 2013. “Characteristics of Adult Learners with Implications for Online Learning Design.” AACE Journal,editlib.org/d/24286. Accessed on April 23, 
Derwing, Tracey. M. 2009. “Utopian Goals for Pronunciation Teaching." Proceedings of the 1st Pronunciation in Second Language Learning and Teaching Conference. Iowa: Iowa State University.

Gay, L. R., and Peter Airasian. 2000. Educational Research: Competencies for Analysis and Application. New Jersey: Prentice-Hall.

Giles, Sophie. 2003. "Social Support Provision and Cultural Values in Indonesia and Britain.” Journal of Cross-Cultural Psychology, Vol. 34, No. 10,

Hillier, Yvonne. 2002. Reflective Teaching in Further and Adult Education. London: Continuum,

Lee, Jia-Ying. 2011. "English Learning Styles of Students from East Asian Countries: a Focus on Reading Strategies.” International Education Studies, Vol. 4, No. 2,

O’Neal, George. 2013. “The Effects of the Presence and Absence of Suprasegmental on the Intelligibility and Assessment of an Expanding-Circle English According to Other Expanding-Circle English Listeners." dspace.lib.niigata-u.ac.jp:8080/dspace/bitstream/.../1/15_65-87.pdf.

Accessed on April 12.

Suwartono, T. and Puspita Mayaratri. 2011. "Handling the EFL Students’ Crisis of Self-confidence to Ask Questions.” Sino-US English Teaching, Vol. 8, No. 1 ,

Suwartono. 2012. “Songs Helped Them Learn the English Connected Speech.” Proceedings of International Conference on English Language and Literature (ICELL),

Suwatno. 2012. "Pengembangan Media VCD Konteks Pertanian pada Pembelajaran Bahasa Indonesia Aspek Mendengarkan dan Menulis Pengumuman di SD/MI Kelas IV Semester 2.” Seloka: Jurnal Pendidikan Bahasa dan Sastra Indonesia, Vol. 1, No. 1.

Thompson, T., and Matt Gaddes. 2005.“The Importance of Teaching Pronunciation to Adult Learners.” Asian EFL Journal, Vol. 2.

Wenden, Anita. 1991. Learner Strategies for Learner Autonomy: Planning and Implementing Learner Training for Language Learners. Hertfordshire: Prentice Hall Europe,

Wulandari, A., Malikatul Laila, and Aryati Prasetyarini. 2008. “Improving Students' Pronunciation Using Audio Visual Aids (AVAs) at the Fifth Year of Al-Azhar Syifa Budi Elementary School of Surakarta in Academic Year 2007/2008 (a Classroom Action Research).” Kajian Linguistik dan Sastra, Vol. 20, No. 1. 